\title{
Transmitter Power Control For Fixed and Mobile Cognitive Radio Adhoc Networks
}

\author{
Vikas $^{1}$, V. R. Singh ${ }^{2}$ \\ ${ }^{I}$ (Dept. of Electronics and Communication Engineering, University Institute of Engineering and Technology, \\ Maharshi Dayanand University Rohtak-124001, Haryana, India) \\ ${ }_{2}^{2}$ (Prabhu Dayal Memorial College of Engineering, Bahadurgarh-124507, Haryana, India)
}

\begin{abstract}
In cognitive radio adhoc networks, licensed users are known as primary users and unlicensed users are secondary users. The unlicensed users need to access the spectrum of licensed users with negligible interference to primary and other secondary users. Hence proper power transmission control is important to ensure interference free transmission. Location awareness is also helpful for concurrent transmission and reception region where secondary and primary users can coexists. In this research paper we examined spectrum sharing state without spectrum sensing of fixed and mobile cognitive radio adhoc networks. In proposed algorithm of power control the cognitive radio adhoc networks achieves quality of communication with maximum throughput of power without causing interference to primary and other secondary users. The results obtained shows that the planned algorithm can provide energy efficient transmission and increased packet delivery ratio without compromising their required quality of service.
\end{abstract}

Keywords - Adhoc networks, Cognitive radio, Primary user, Power control, Secondary user.

\section{INTRODUCTION}

In present days the wireless communication uses licensed spectrum policy. Such licensed spectrum policy results inefficient spectrum utilization [10]. For proper utilization of spectrum cognitive radio technique can be used. The spectrum allocated users are primary users and the same spectrum used by other/unlicensed users is known as secondary users [11][12]. The secondary users use the primary/licensed spectrum when the transmission of primary base station is off or location awareness allows the secondary user to use the licensed spectrum where the signal strength of primary base station is low or there is no primary receiver in the range of secondary transmission so that the secondary transmission will not interfere the primary signal [4][8].

There are some challenges occurs during implementation of cognitive radio networks [6][7].

1. The cognitive radio signals should not interfere with licensed users of spectrum.

2. The strength of the secondary transmission should be highest so that the secondary receiver can receive signals properly.

3. If the cognitive radio transmitter/receiver is mobile then the communication becomes extremely difficult.
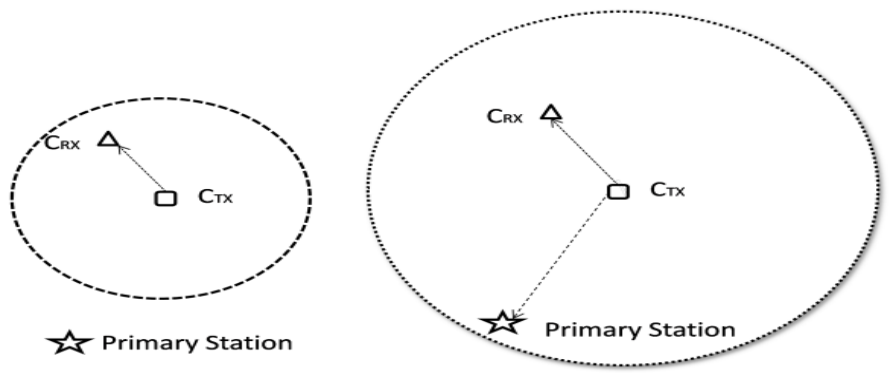

Figure 1: Spectrum sharing with and without power control.

Power control is applied for avoiding the interference to the primary users but it has no guarantee of quality of service to the secondary users. If the signal strength of secondary user is not enough for communication then that channel may not having opportunity for cognitive radio communication.[1][2][3]

Figure 1 shows that when we transmit fixed power with no change then the transmitted signal interfere the primary station $\left(2^{\text {nd }}\right.$ image $)$ but when the transmitted power of cognitive radio transmitter optimise then it will not interfere the primary station( $\left(1^{\text {st }}\right.$ image). 
Table 1

NOTATION TABLE

\begin{tabular}{|c|c|}
\hline Notation & Description \\
\hline$\Theta_{1}$ & Positioning angle of $\mathrm{P}_{\mathrm{RX}}$ \\
\hline$\Theta_{2}$ & Positioning angle of $\mathrm{C}_{\mathrm{RX}}$ \\
\hline$\Phi_{\mathrm{CP}}$ & Angle between $\mathrm{C}_{\mathrm{RX}}$ and $\mathrm{P}_{\mathrm{RX}}$ \\
\hline $\mathrm{R}_{1}$ & Distance between $\mathrm{P}_{\mathrm{TX}}$ and $\mathrm{C}_{\mathrm{RX}}$ \\
\hline $\mathrm{R}_{2}$ & Distance between $\mathrm{P}_{\mathrm{TX}}$ and $\mathrm{P}_{\mathrm{RX}}$ \\
\hline $\mathrm{D}_{12}$ & Distance between $\mathrm{P}_{\mathrm{RX}}$ and $\mathrm{C}_{\mathrm{TX}}$ \\
\hline $\mathrm{D}_{22}$ & Distance between $\mathrm{C}_{\mathrm{TX}}$ and $\mathrm{C}_{\mathrm{RX}}$ \\
\hline $\mathrm{D}_{\mathrm{CP}}$ & Distance between $P_{R X}$ and $C_{R X}$ \\
\hline$R$ & Decodable radius of $\mathrm{P}_{\mathrm{TX}}$ \\
\hline $\mathrm{W}_{\mathrm{R}}$ & Receiving signal power \\
\hline $\mathrm{W}_{\mathrm{CTX}}$ & Transmitting power of $\mathrm{C}_{\mathrm{TX}}$ \\
\hline $\mathrm{W}_{\text {PTX }}$ & Transmitting power of $\mathrm{P}_{\mathrm{TX}}$ \\
\hline $\mathrm{A}_{\mathrm{T}}$ & Transmitting antenna gain \\
\hline$A_{R}$ & Receiving antenna gain \\
\hline $\mathrm{L}_{\mathrm{T}}$ & Height of transmitting antenna \\
\hline $\mathrm{L}_{\mathrm{R}}$ & Height of receiving antenna \\
\hline $\operatorname{SIRP}_{\mathrm{R}}$ & Signal to interference ratio for $\mathrm{P}_{\mathrm{RX}}$ \\
\hline $\mathrm{SIRC}_{\mathrm{R}}$ & Signal to interference ratio for $C_{R X}$ \\
\hline$\Psi_{\mathrm{P}}$ & SIR thresholds for $\mathrm{P}_{\mathrm{RX}}$ \\
\hline$\Psi_{\mathrm{C}}$ & SIR thresholds for $C_{R X}$ \\
\hline$\gamma$ & Path loss \\
\hline$R_{\text {CONTX }}$ & Radius of concurrent transmission \\
\hline
\end{tabular}

\section{SYSTEM MODELING}

The spectrum sharing scenario shown in figure 2, where star shows the primary transmitter and diamond shape shows the primary receiver. Triangle shape and square are cognitive radio transmitter and receiver. The $C_{T X}$ and $C_{R X}$ form adhoc network and use same spectrum band of primary network. Let us assume that the $\mathrm{P}_{\mathrm{TX}}$ lies at the origon of the coordinates axies, and the primary receiver is fixed at its position. Assume that the location of primary receiver and cognitive receiver is $\left(R_{2}, \theta_{1}\right)$ and $\left(R_{1}, \theta_{2}\right)$. The $P_{T X}$ transmitter range is $R$ and distance between $\mathrm{C}_{\mathrm{RX}}$ and $\mathrm{C}_{\mathrm{TX}}$ is $\mathrm{D}_{22}$ and $\mathrm{C}_{\mathrm{TX}}$ and $\mathrm{P}_{\mathrm{RX}}$ is $\mathrm{D}_{12}$.

So the distance between $P_{R X}$ and $C_{R X}$ is

$$
D_{C P}=\sqrt{R_{1}^{2}+R_{2}^{2}-2 R_{1} R_{2} \cos \emptyset_{C P}}
$$




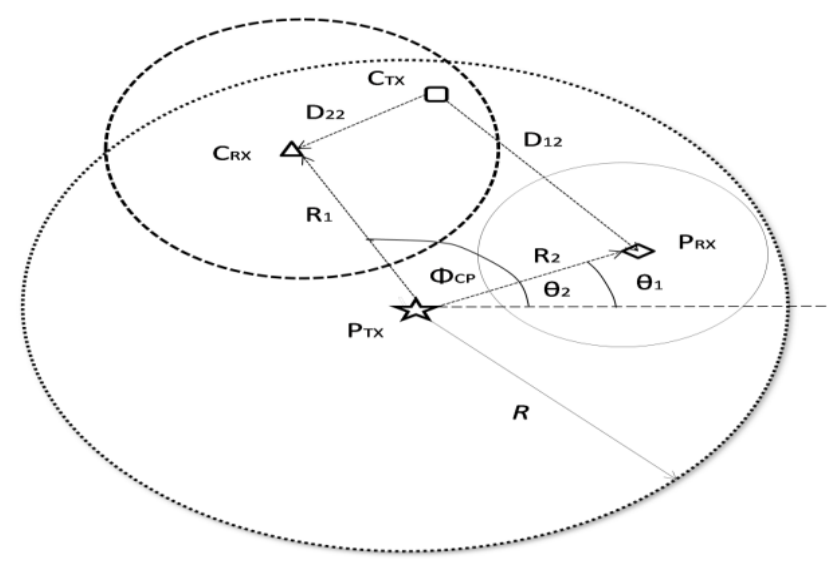

Figure 2: System model layout of cognitive radio adhoc network using spectrum of primary spectrum.

The signal power received at receiving antenna is

$$
W_{R}=\frac{W_{T} A_{T} A_{R} L_{T}^{2} L_{R}^{2}}{D^{R}}
$$

For concurrent transmission the secondary user must satisfy signal to interference ratio requirements for both $\mathrm{P}_{\mathrm{RX}}$ and $\mathrm{C}_{\mathrm{RX}}$. The signal to interference thresholds is denoted by $\Psi_{p}$ and $\Psi_{C}$ for $\mathrm{P}_{\mathrm{RX}}$ and $\mathrm{C}_{\mathrm{RX}}$. For the concurrent transmission region the optimal power control problem formulated as follows.

To increase area of concurrent transmission region

$$
\begin{aligned}
& \operatorname{SIRP}_{R}>\Psi_{P} \\
& \operatorname{SIRC}_{R}>\Psi_{C} \\
& W_{C}^{\min } \leq W_{C T X} \leq W_{C}^{\min }
\end{aligned}
$$

\section{Power Control Optimisation:-}

Let us assume that the gain is unity for transmitting and receiving antenna. The path loss factor is same for primary and secondary transmission [5][9]. Antenna heights are same. So the signal to interference ratio can be written as

$$
\begin{aligned}
& \operatorname{SIRC}_{R}=\frac{W_{C T X} R_{1}}{W_{P T X} D_{22}^{Y}} \\
& S I R P_{R}=\frac{W_{P T X} D_{12}^{Y_{1}}}{W_{C T X} R_{2}^{Y}}
\end{aligned}
$$

Since the signal to interference ratio must satisfy equation no. 3,4 and 5 , we have

$$
\begin{aligned}
& D_{22}<R_{1}\left(\frac{W_{C T X X}}{\Psi_{C} W_{F T X}}\right)^{\frac{1}{Y}} \\
& D_{12}>R_{2}\left(\frac{\Psi_{F} W_{C T X}}{W_{F T X}}\right)^{\frac{1}{Y}}
\end{aligned}
$$

$1^{\text {st }}$ condition: - Eq. (8) and (9) means that the $\mathrm{C}_{\mathrm{TX}}$ can transmit the signal to $\mathrm{C}_{\mathrm{RX}}$ but subject to the condition that the $\mathrm{C}_{\mathrm{TX}}$ must lies in the circle centred at $\mathrm{C}_{\mathrm{RX}}$ having radius eq. 8 .

$2^{\text {nd }}$ condition: - The $C_{T X}$ must not enter in the circle centred at $P_{R X}$ with a radius eq. 9

There for the transmission region is concurrent at its maximum level when satisfies following equation. 


$$
D_{C P}=R_{1}\left(\frac{W_{C T X}}{T_{C} W_{F T X}}\right)^{\frac{1}{P}}+R_{2}\left(\frac{\Psi_{F} W_{C T X}}{W_{F T X}}\right)^{\frac{1}{Y}}
$$

The optimal power of transmission can be derived by eq. 10. Let's consider eq. 3,4,5 and solution of 10 not lie in allowed circles of receivers range. So we consider two cases. We have two functions of $R_{1}$ and $\Phi_{\mathrm{CP}}$.

$$
\begin{aligned}
& G\left(R_{1}, \emptyset_{C P}\right)=R_{2}\left(\frac{\Psi_{F} W_{C X X}^{\min }}{W_{P T X}}\right)^{\frac{1}{\gamma}}+R_{1}\left(\frac{W_{C T X}^{\min }}{\Psi_{C} W_{P T X}}\right)^{\frac{1}{\gamma}}-\sqrt{R_{2}^{2}+R_{1}^{2}-2 R_{2} R_{1} \cos \emptyset_{C P}} \\
& l\left(R_{1}, \emptyset_{C P}\right)=R_{2}\left(\frac{\Psi_{F} W_{T T X}^{\max }}{W_{P T X}}\right)^{\frac{1}{\gamma}}+R_{1}\left(\frac{W_{C T X}^{\max }}{\Psi_{C} W_{P T X}}\right)^{\frac{1}{\gamma}}-\sqrt{R_{2}^{2}+R_{1}^{2}-2 R_{2} R_{1} \cos \emptyset_{C P}}
\end{aligned}
$$

$\mathrm{G}\left(\mathrm{R}_{1}, \Phi_{\mathrm{CP}}\right)>0$ The circle having centre $\mathrm{P}_{\mathrm{RX}}$ and $\mathrm{C}_{\mathrm{RX}}$ overlap each other then the $\mathrm{W}_{\mathrm{CTX}}$ can't be increased and it will not reach at optimizing stage.

$\mathrm{J}\left(\mathrm{R}_{1}, \Phi_{\mathrm{CP}}\right)<0$ Then both the circles not overlapped then the power will not optimize. Hence the optimal power depends on $R_{1}$ and $\Phi_{C P}$.

$$
\left[\left(R_{1}, \emptyset_{C P}\right) \mid G\left(R_{1}, \emptyset_{C P}\right) \leq 0 \cap J\left(R_{1}, \emptyset_{C P}\right) \geq 0\right]
$$

\section{Algorithm for fixed $\mathrm{C}_{\mathrm{RX}}$}

Step 1: Refresh the present values of $\theta_{1}, \theta_{2}, R_{1}, R_{2}$.

Step 2: Find out values of $\mathrm{D}_{22}, \Phi_{\mathrm{CP}}, \mathrm{G}\left(\mathrm{R}_{1}, \Phi_{\mathrm{CP}}\right)$ and $\mathrm{J}\left(\mathrm{R}_{1}, \Phi_{\mathrm{CP}}\right)$.

Step 3: If we find the following condition

$\mathrm{G}\left(\mathrm{R}_{1}, \Phi_{\mathrm{CP}}\right) \leq 0 ; \mathrm{J}\left(\mathrm{R}_{1}, \Phi_{\mathrm{CP}}\right) \geq 0$ and

$\mathrm{D}_{22} \leq$ Maximum range of $\mathrm{C}_{\mathrm{TX}}$.

At this stage we calculate the optimal power and cognitive radio transmitter transmit optimal power.

Step 4: Or If we find following another condition

$\mathrm{J}\left(\mathrm{R}_{1}, \Phi_{\mathrm{CP}}\right)<0$ and

$\mathrm{D}_{22} \leq$ Maximum range of $\mathrm{C}_{\mathrm{TX}}$.

Then there will be no interference occurs between primary and secondary transmission. So at this stage we can transmit with full power for increased data rate and quality of communication.

Step 5: Or If we find following another condition

$\mathrm{G}\left(\mathrm{R}_{1}, \Phi_{\mathrm{CP}}\right)>0$

Then transmission is not possible. At this stage we can't increase the transmission power desired level of communication. So at this stage we have to stop transmission in this spectrum.

\section{Power control for mobile $\mathrm{C}_{\mathrm{RX}}$ :-}

If we consider mobility of $C_{R X}$ then due to mobility $R_{1}$ and $\Phi_{C P}$ also changes with change in position of $C_{R X}$. From fig 3 we consider the movement of $C_{R X}$ from $X$ position to $Y$ position. We assume that $C_{T X}$ is in fixed position $\left(\mathrm{R}_{3}, \theta_{3}\right)$ and $\mathrm{C}_{\mathrm{RX}}$ changes its position from $\left(\mathrm{R}_{1}, \theta_{2}\right)$ with velocity $\vec{V}$

$$
\vec{V}=Z \vec{k}
$$

Here $\mathrm{Z}$ is speed and $\vec{k}$ is unit directional vector

$$
\vec{k}=(\cos \beta, \sin \beta)
$$




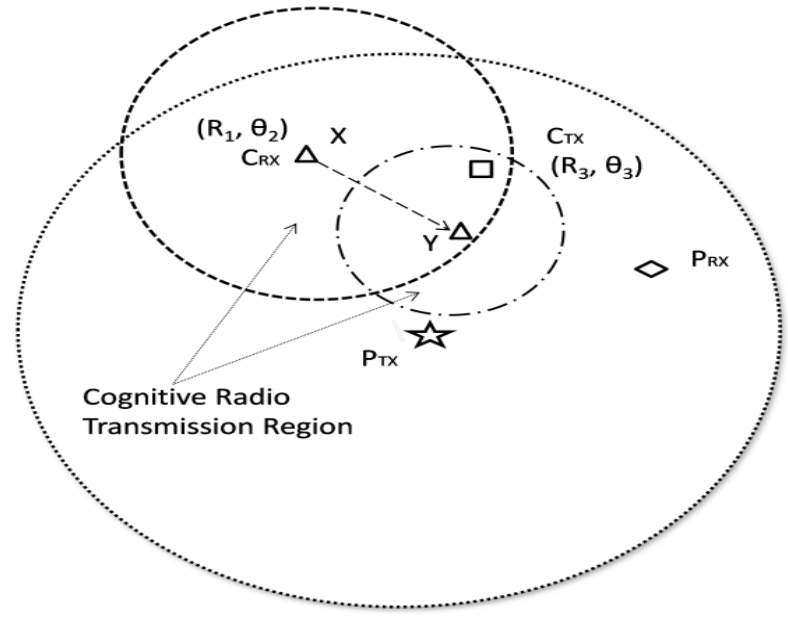

Figure 3: Transmission region variation with change the position of cognitive radio receiver.

So the polar coordinates of $\mathrm{C}_{\mathrm{RX}}$ written as

$$
\begin{aligned}
& R_{1}(t)=\sqrt{\left(R_{1}^{s} \cos \theta_{2}+Z t \cos \beta\right)^{2}+\left(R_{1}^{s} \sin \theta_{2}+Z t \sin \beta\right)^{2}} \\
& \theta_{2}(t)=\arctan \frac{R_{1} \sin \theta_{2}+Z t \sin \beta}{R_{1} \cos \theta_{2}+Z t \cos \beta}
\end{aligned}
$$

If $\mathrm{C}_{\mathrm{RX}}$ at its fixed position then the coordinates of $\mathrm{C}_{\mathrm{RX}}$ remains same hence the $\mathrm{C}_{\mathrm{TX}}$ transmits the optimal power. But if the position of the $\mathrm{C}_{\mathrm{RX}}$ changed with time then the $\mathrm{C}_{\mathrm{RX}}$ send its new location coordinates of $\mathrm{C}_{\mathrm{TX}}$ so that the $\mathrm{C}_{\mathrm{TX}}$ compute new optimal power for transmission.

\section{Algorithm for moving $\mathrm{C}_{\mathrm{RX}}$ :-}

Step 1: Refresh the present values of $\theta_{1}, \theta_{2}, R_{1}^{s}, R_{2}, R_{3}, Z$ and $\vec{k}$ and Calculate $R_{1}, \theta_{2}, \Phi_{C P}$ and $D_{22}$

Step 2: If we find the following condition

$\mathrm{D}_{22} \leq$ Radius of concurrent transmission area

$\mathrm{D}_{22} \leq$ Maximum range of $\mathrm{C}_{\mathrm{TX}}$

At this stage the cognitive radio transmitter and receivers is in concurrent transmission area. So the transmission power remains same.

Step 3: Otherwise we calculate

$$
\mathrm{G}\left(\mathrm{R}_{1}, \Phi_{\mathrm{CP}}\right) \text { and } \mathrm{J}\left(\mathrm{R}_{1}, \Phi_{\mathrm{CP}}\right) \text {. }
$$

Step 4: If we find the following conditions

$\mathrm{G}\left(\mathrm{R}_{1}, \Phi_{\mathrm{CP}}\right) \leq 0 ; \mathrm{J}\left(\mathrm{R}_{1}, \Phi_{\mathrm{CP}}\right) \geq 0$ and

$\mathrm{D}_{22} \leq$ Maximum range of $\mathrm{C}_{\mathrm{TX}}$

At this stage we calculate the optimal power and find concurrent transmission radius and cognitive radio transmitter transmit optimal power.

Step 5: Or if we find following conditions

$\mathrm{J}\left(\mathrm{R}_{1}, \Phi_{\mathrm{CP}}\right)<0$ and

$\mathrm{D}_{22} \leq$ Maximum range of $\mathrm{C}_{\mathrm{TX}}$

Then there will be no interference occurs between primary and secondary transmissions. So at this stage we can transmit with full power for increased data rate and quality of communication.

Step 6: Or If we find $\mathrm{J}\left(\mathrm{R}_{1}, \Phi_{\mathrm{CP}}\right)>0$

Then transmission is not possible. At this stage we can't increase the transmission power at desired level of communication. So for this condition stop transmission in this spectrum. 
III.

\section{RESULTS}

Table 2

SIMULATION PARAMETERS

\begin{tabular}{|c|c|}
\hline $\mathrm{W}_{\text {PTX }}$ & $110 \mathrm{~kW}$ \\
\hline Minimum $\mathrm{W}_{\mathrm{CTX}}$ & $2 \mathrm{~W}$ \\
\hline Maximum $\mathrm{W}_{\mathrm{CTX}}$ & $90 \mathrm{~W}$ \\
\hline$\gamma$ & 4 \\
\hline$\Psi_{\mathrm{C}}$ & $2 \mathrm{db}$ \\
\hline$\Psi_{\mathrm{P}}$ & $27 \mathrm{db}$ \\
\hline Coordinates of $\mathrm{P}_{\mathrm{RX}}$ & $\left(40 \mathrm{~km}, 5^{\circ}\right)$ \\
\hline Coordinates of $\mathrm{C}_{\mathrm{TX}}$ & $\left(40 \mathrm{~km}, 70^{\circ}\right)$ \\
\hline Simulation Time & $1500 \mathrm{~s}$ \\
\hline
\end{tabular}

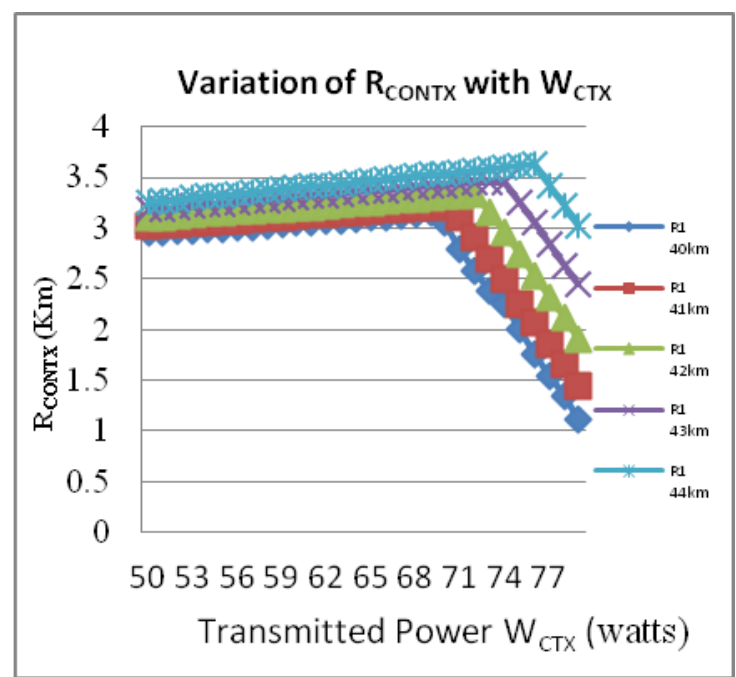

Figure 4: Power transmitted vs. concurrent transmission radius

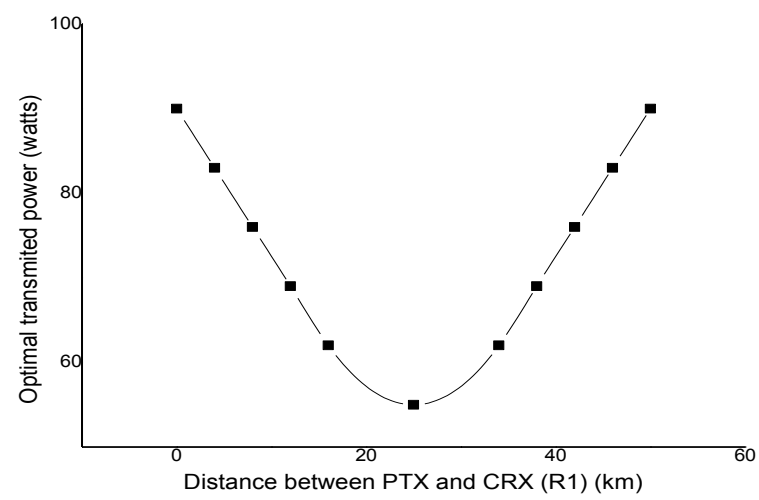

Figure 5: Optimal power transmitted at $\Phi_{\mathrm{CP}}$ is $70^{\circ}$ 


\section{Packet delivery ratio with power control algorithm}

Consider path loss factor for primary and secondary transmission is 2 and 3, and the average speed of cognitive radio receiver is $35 \mathrm{~m} / \mathrm{s}$ and standard deviation is $5 \mathrm{db}$. As per results the data transmission is decreased with increase in speed of $\mathrm{C}_{\mathrm{RX}}$.

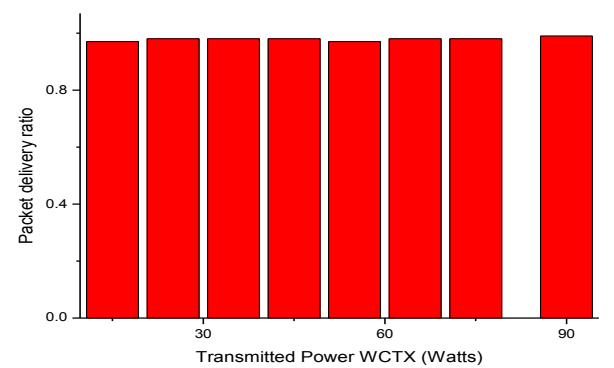

Figure 6: Data transfer in packets when $C_{R X}$ moving at average speed $15 \mathrm{~m} / \mathrm{s}$

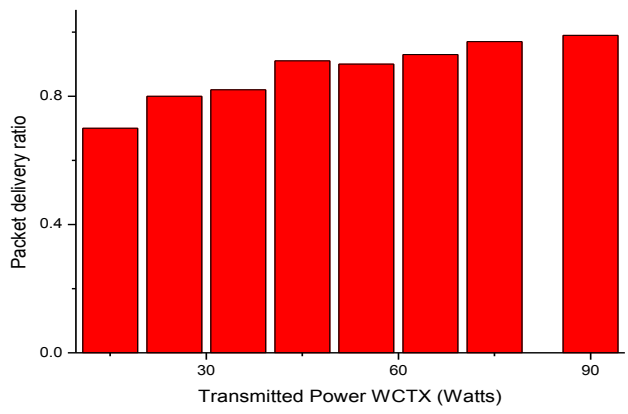

Figure 7: Data transfer in packets when $C_{R X}$ moving at average speed $25 \mathrm{~m} / \mathrm{s}$

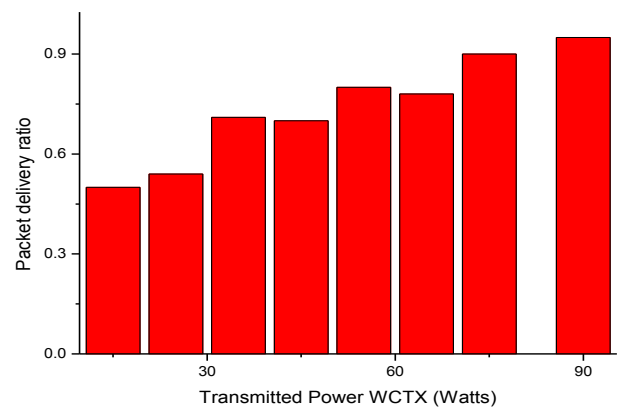

Figure 8: Data transfer in packets when $\mathrm{C}_{\mathrm{RX}}$ moving at average speed $35 \mathrm{~m} / \mathrm{s}$

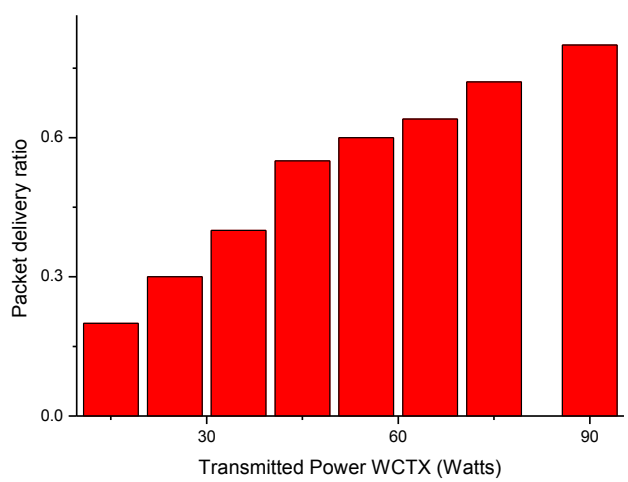

Figure 9: Data transfer in packets when $C_{R X}$ moving at average speed $45 \mathrm{~m} / \mathrm{s}$ 
As per results with increase in speed the packet delivery ratio decreases but on other hand if the transmitter power increases the packet transmission have less effected and we get satisfactory results. If the transmission power reaches to optimal power then data transmission is at its satisfactory higher value.

\section{CONCLUSION}

In this paper transmission power control for cognitive radio transmitter is formulated for same frequency spectrum of primary user. The designed algorithms are suitable for fixed and mobile cognitive radio receivers and enhance the concurrent transmission area and improve the power transmission for quality of service. The result shows the data transmission effectively improved during fixed and mobile cognitive radio receivers due to optimized transmission power. In this paper we have consider only one cognitive radio adhoc network and optimize its transmission power. For the future scope we can consider multiple cognitive radio adhoc networks simultaneously for power optimization.

\section{REFERENCES}

1]. Ba Lam To, Thi Mai Trang Nguyen, Guy Pujolle, Flow-Based Power Control in Cognitive Radio Ad-Hoc Network, in IEEE, 978-1-4577-1379-8/2012.

2]. S. M. S'anchez, S. B. Mafra, R. D. Souza, E. M. G. Fernandez, Power-Rate Control with Directional transmission and Reception in a Cognitive Radio Network, IEEE, 978-1-4799-3743-1/2014.

3]. S. Sun, J. Di, and W. Ni, Distributed power control based on convex optimization in cognitive radio networks, in International Conference on Wireless Communications and Signal Processing (WCSP), oct. 2010, pp. 1-6.

4]. U. Habiba, Z. Hossain, and M. Matin, Robust power control using iteratively reweighted least square (irls) for cognitive radio networks, in IEEE International Conference on Communication Systems (ICCS), nov. 2010, pp. 564-568.

5]. H. Celebi and H. Arslan, Adaptive positioning system for cognitive radios, in Proc. IEEE DySPAN, April 2007, pp. 78-84.

6]. N. Hoven and A. Sahai, Power scaling for cognitive radio, in Proc. of International Conference on Wireless Networks, Communications and Mobile Computing, 2005, pp. 250-255.

7]. J. Tang and X. Zhang, Quality-of-service driven power and rate adaptation for multichannel communications over wireless links, IEEE Transactions on Wireless Communications, vol. 6, no. 12, pp. 4349-4360, December 2007.

8]. E. C. Y. Peh, Y.-C. Liang, and Y. Zeng, Sensing and power control in cognitive radio with location information, in ICCS, 2012, pp. $255-259$.

9]. Y. Song and J. Xie, Optimal Power Control for Concurrent Transmissions of Location-Aware Mobile Cognitive Radio Ad Hoc Networks, in GLOBECOM, no. July, 2009, pp. 1-6.

10]. M. R. Hassan, G. Karmakar, and J. Kamruzzaman, Maximizing the concurrent transmissions in cognitive radio ad hoc networks, in IWCMC, no. July, 2011, pp. 466-471.

11]. M. Marcus, Unlicensed Cognitive Sharing of TV Spectrum, IEEE Comm. Mag., pp.24-25, May 2005.

12]. FCC, Unlicensed operation in the TV broadcast bands, ET Docket No. 04-186; additional spectrum for unlicensed devices below $900 \mathrm{mhz}$ and in the $3 \mathrm{ghz}$ band, ET Docket No. 02-380, FCC 04-113. [Online]. Available: http://hraunfoss.fcc.gov/edocspublic/attachmatch/FCC-04-113AI .pdf 